\title{
Performance Estimation and Control Analysis of AC-DC/DC- DC Hybrid Multi-Port Intelligent Controllers Based Power Flow Optimizing Using STEM Strategy and RPFC Technique
}

\author{
C. Nagarajan ${ }^{1, *}$, B. Tharani ${ }^{2}$, S. Saravanan ${ }^{3}$, R. Prakash ${ }^{3}$ \\ ${ }^{1}$ Muthayammal College of Engineering, Rasipuram, India \\ ${ }^{2}$ Sri Sakthi Institute of Engineering and Technology, Coimbatore, India \\ ${ }^{3}$ Muthayammal Engineering College, Rasipuram, India \\ ${ }^{1}$ nagaraj2k1@gmail.com \\ *Corresponding Author
}

\section{ARTICLE INFO}

\section{Article history}

Received January 05, 2022

Revised February 02, 2022

Accepted February 18, 2022

Keywords

Deferrable load;

Hybrid Energy Management;

Energy storage system;

Substantial Transformative

Energy Management (STEM)

Strategy;

Resilient Power Flow Control (RPFC)

\begin{abstract}
The control system will measure the renewable energy generation power, and if the generated power is equal to the grid power, the generation sources are directly connected to the load system. When the power generation is not at sustaining level, the controller will optimize the source using the DCDC converter and Battery based Energy management system. The operation of the battery system depends upon the power generation availability of renewable energy resources. During the high power RES, the battery is charging condition. When the RES is low power means the battery is in discharged condition. Also, the fuel cell-based energy compensation will take place when the battery power is low. The Energy router will monitor all the above generation plants based on the threshold values of each power plant, substantial Transformative Energy Management (STEM) Strategy and Resilient Power Flow Control (RPFC) controller takes necessary action like which power plant is connected to the grid power system. The simulation is performed on Mat lab / Simulink simulation platforms, and the results show the effectiveness and reliability of the control strategy for micro-grid interconnection and flexible energy flow correspondence.
\end{abstract}

This is an open-access article under the CC-BY-SA license.

\section{Introduction}

The Renewable Energy Sources (RES) are natural dependent. Due to this, there is no stable power generation in the system. The energy router-based grid-connected hybrid system power flow management control is introduced in this system for energy stabilization. The purpose of the energy router is to meet the load requirement and improve the power flow from sources to the grid system. Due to this condition, the DC-DC converter is utilized to improve renewable energy generation. Based on the proper Pulse Width Modulation (PWM) strategy, the conversion efficiency will be determined. Due to technological advances in intelligent, multifunctional energy converters and router energy (ERS) are analyzed energy flows in the renewable energy system also improving the energy in the grid system (or) load. The improvements of the energy AC-DC Hybrid Multiport system for stability in the proposed system needs to identify the drawback in the conventional methods that are given below. 
The purpose of a generic configuration based on hybrid AC / DC Multi-Port and Multi-Function Grid and equivalent circuits and mathematics modeling in MPMF-PET [1]. The purpose of enhancing the power in the grid system is two-stage of compensation in the process [2]. In a further stage, the Zero sequence Voltage vector is used in the cascaded H-bridge-based grid interconnected with a hybrid AC/DC multi-port system for stabilizing the power flow [3][4]. Multi-port power electronic transformers are used to achieve high-speed hybridization of Alternating Current (AC) and DC multistage and various distributed renewable energy sources. In detail, the functions of the reliable and AC / DC hybrid power system are analyzed, and the simulations are carried out by computer and power reliability calculations [5].

Multi-port DC-DC-AC (MP-DC-AC) converters offer the ability to convert power into a single converter configuration between two DC systems and AC systems. Possible benefits include reduced energy conversion levels [6-8]. The Very Large Scale Integration (VLSI) technology enables to development of reliable Low Voltage Direct Current (LVTC) [9] and supply network competitive power converters. In terms of traditional dual-loop control, the three-stage AC / DC converter with its bilateral power flow and a unit power factor on the $\mathrm{AC}$ side can act as a link bridge in a hybrid microgrid [10]. Research on conventional optimization planning almost all AC / DC hybrid power systems are Voltage Source Control (VSC)-based this is the most efficient control strategy for hybrid system [11][12]. Multi-input converter rendering integrates actively controlled Hybrid Energy Storage System (HESS) and front-end AC-DC power factor correction (PFC) converter [13][14]. An integrated power Load Flow (LF) model For the AC-DC Hybrid Distribution System (DSS). Proposed Models can be used in hybrid Distribution Systems (DS) and hybrid configurations of AC / DC bus and AC / DC lines. A new assortment of DS and LF analyses is also introduced [15-17].

The converter can connect multiple DC buses to different voltages and enable port voltage to control power flow. A new resonant ZCS multi-input / multi-output converter is provided. Each of the desired power input ports is sent to each of the output ports independently of the converter [18-20]. The system is also given the ability to operate in both directions.

Substantial Transformative Energy Management (STEM) and Resilient Power Flow Control (RPFC) Algorithms are improving energy stability in the grid system [21-25]. The two control technologies based on hybrid power systems have the advantages of flexibility, efficiency, reliability, emission, and economic standards, more like power generation. It will be organized as follows: The entire system is structured, including an interconnected microgrid and main grid, and a power router, analytical model of the DC-DC converter and the Inverter are performance are evaluated. The simulated Matlab / Simulink Simulation 2017b platform demonstrates the effectiveness and reliability of the presented interconnected framework and its associated energy control strategy.

From the above analysis, the research contribution of the proposed techniques has been analyzed with the different parameters like Execution time (sec), Steady-state error (\%), THD (\%), and Efficiency in (\%), which need to be improved of the system performance, the proposed hybrid multiport converter system will improve the performance system also considering the above parameters improvements.

\section{Proposed STEM and RPFC system}

The proposed hybrid converter is designed to integrate DC / DC converters with DC / AC inverters operating on any dynamic condition to provide a Stabilized power grid and load system. The additional benefits interconnected structure it is used to increase the rated power reduce input current ripple, output voltage ripple, power loss, and efficiency. By switching the proper pulse to the proposed converter efficiency of the system is enhanced by the use of energy-saving inductors. Also, the bidirectional converter saves energy during the normal condition, and it provides power during an uncertain state. The proposed STEM and RPFC techniques improve converter performance and provide stability under critical conditions. The energy routers will analyze the power flow operation of the proposed model. The detailed Operating principles and design considerations have been proposed system shown in Fig. 1. 


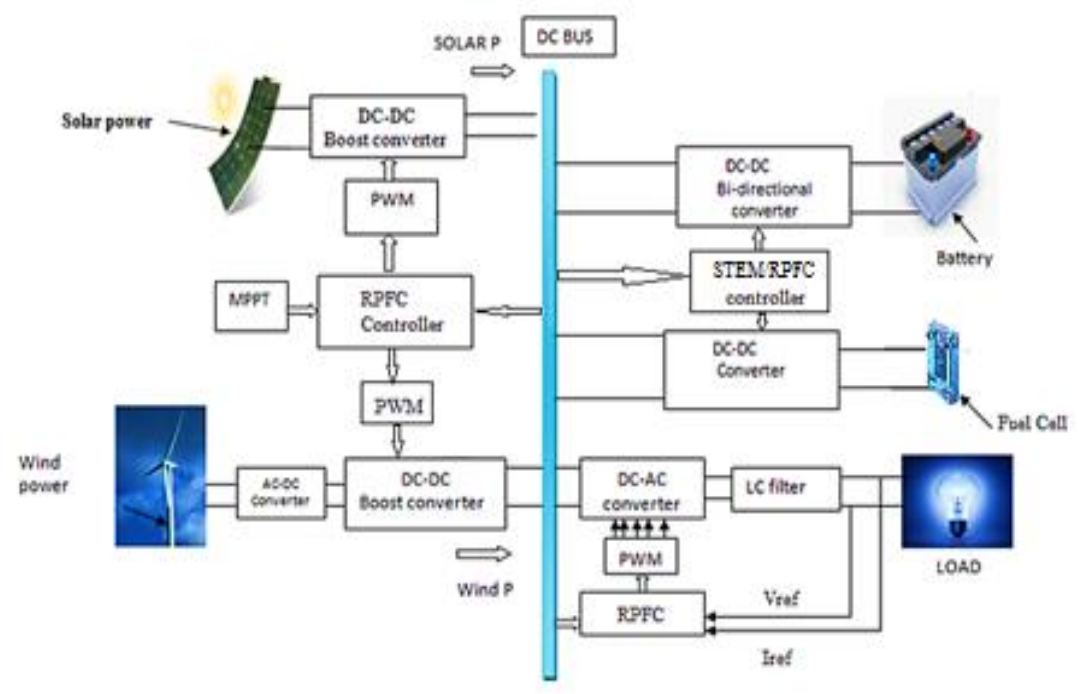

Fig. 1. The block diagram for the Multi-Port Converter

\subsection{Solar PV Array Module and Equivalent circuit}

The SPV system consists of several solar cells, which are connected in series and in parallel to generate voltage. Typically, an SPV frame provides a non-linear voltage. If the solar rays hit the silicon PV cells, they will generate energy according to the irradiance level. The output of each SPV cell is derived from solar radiation and changes periodically. The equivalent circuit-based solar power generations are described below. The equivalent circuit model of the photovoltaic module based on the single diode model designed for is shown in Fig. 2. This model of PV is used for all applications because its structure is simple and more reliable than other multi-diode models. The PV module designed using the equivalent circuit must match the real-time parameters of a practical PV panel like open circuit voltage, short circuit current, maximum voltage, and power rating.

$$
I=I_{p h}-I_{d}\left[\exp \left(\frac{q\left(V+I R_{S}\right)}{K T_{C} A}-1\right)\right]-\left(V+I R_{S}\right) / R_{P}
$$

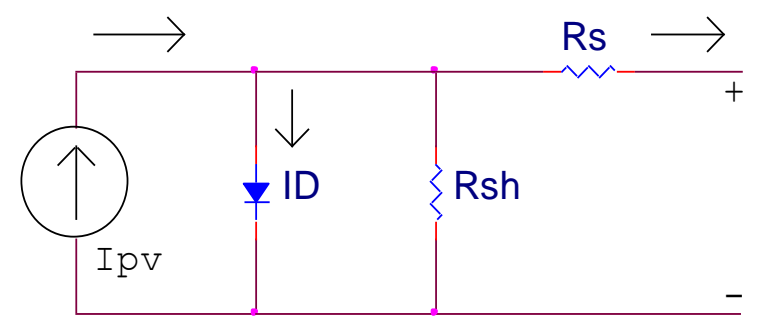

Fig. 2. Equivalent circuit

In order to extract maximum power from a given solar array, an MPPT (Maximum Power Point Tracking) is employed widely in modeling and for serving as standalone applications. Nominal voltage and current in equation (2) is replaced by $V_{M P P}$ and $I_{M P P}$ is performed by using the proposed MPPT method as

$$
\begin{gathered}
I_{M P P}=N_{P}\left\{I_{p h}-I_{0}\left\{\exp \left(\frac{q_{V_{M P P}}}{n N_{s} K T}\right)\right\}\right\} \\
V_{m p p}=K_{1} * V_{o c} \\
I_{m p p}=K_{2} * I_{s c}
\end{gathered}
$$




\subsection{STEM and RPFC Based MPPT Control System}

In the proposed work, STEM and RPFC based MPPT system is introduced so that the power change of the PV module is analyzed initially. The PV power output is periodically measured and compared with the previously performed power. If the output power increases, the same process will continue. Otherwise, it will interfere with the reversal. PV module voltage is increased or decreased in order to check whether the power is increased or decreased. When increased power increases, the line voltage, which means the operating point of the PV module will be away from the MPP. Accordingly, further interference is required to achieve the MPP rights. Conversely, if the voltage is increased to reduce the power supply line, which means the operating point of the PV module at the left and right of the MPP requires further power to reach MPP. Fig 3 shows the block diagram of STEN and RPFC based MPPT Control System

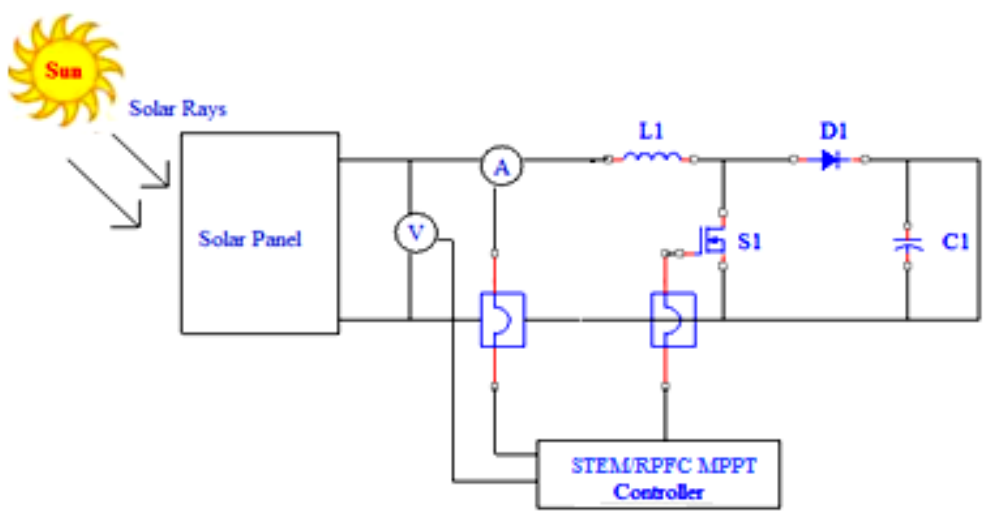

Fig. 3. RPFC based MPPT Control System

\subsection{Wind power Generation}

Wind energy plays a vital role in creating an environmentally sustainable low-carbon economy. This work observes the process of wind energy technologies for wind energy use. The wind stability operation is shown in Fig. 4.

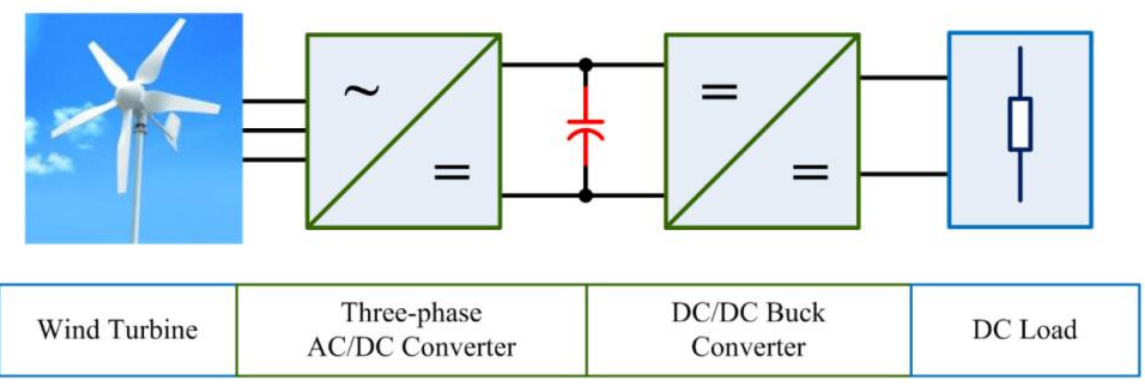

Fig. 4. Overall Block diagram of the wind energy system

According to different aerodynamic characteristics, the wind energy captured by the wind turbine can be expressed as,

$$
\begin{gathered}
P=1 / 2 C p(\lambda, \beta) \rho \pi R^{2} V^{3} \\
\lambda=W R / V \\
P_{\text {max }}=1 / 2 \rho \pi R^{5}
\end{gathered}
$$

Output engine power relative to the WEG characteristics of different wind speeds, where the line shows the unique turbine speed relative to the maximum power point characteristic. The various wind turbine rotation speeds and the different wind speeds V. The MPP of each P-W curve is the wind 
speed. The peak power point of the P-W curve corresponds to DP / DW $=0$. The power generated by different wind turbine speeds produces optimal target control under the generator.

\subsection{Wind Power Generation Circuit Based on AC-DC-DC Converter Operation}

The circuit diagram is based on the proposed wind power generation-based AC-DC-DC converter circuit in Fig. 5. The wind turbine is considered a Wind Generation (WG) source. The output voltage of the AC-DC converter is controlled by the "K" in order to maintain a fixed or constant input voltage even when the WG wind-based AC output voltage changes. The purpose of the DC-DC converter is to provide a regulated (boost) voltage to a load of a fixed DC voltage obtained from the AC-DC converter. The DC-DC converter is controlled by "K1". In Fig. 5, the dynamics of the current flowing from the source DG to the AC-DC converter are given by the equation (9).

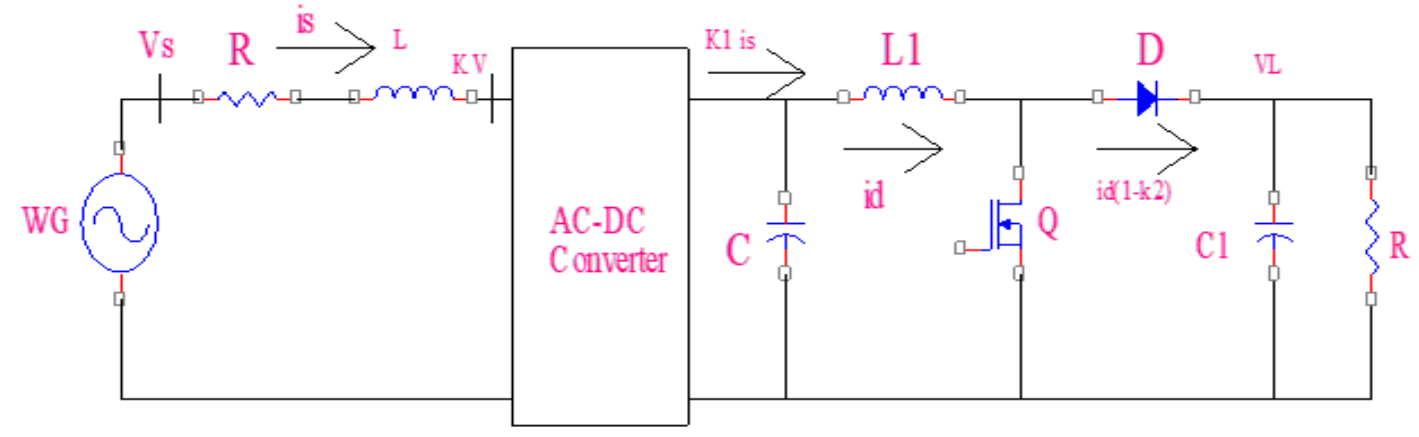

Fig. 5. Circuit diagram for the wind power generation

$$
L \frac{d i_{s}}{d_{t}}=V_{s}-k v-i_{s} R
$$

The dynamic voltage of the capacitor is given in (8),

$$
C=\frac{d_{v}}{d_{t}}=k i_{s}-i_{s}-i_{d}
$$

The dynamic of current through the inductor, $L$, and voltage across the load resistance, $R$, of the DC-DC converter is given by equations (10) and (11)

$$
\begin{aligned}
L_{1} \frac{d i_{d}}{d_{t}} & =V-V_{s}\left(1-K_{1}\right) \\
C_{1} \frac{d V_{L}}{d_{t}} & =i_{d}\left(1-K_{1}\right)-\frac{V_{L}}{R}
\end{aligned}
$$

Equations (8) to (9) represent the nonlinear mathematical model of the entire system shown in Fig. 5. Linearization of equation (10) and equation (11), Mathematical model of state variable representation in the linear system.

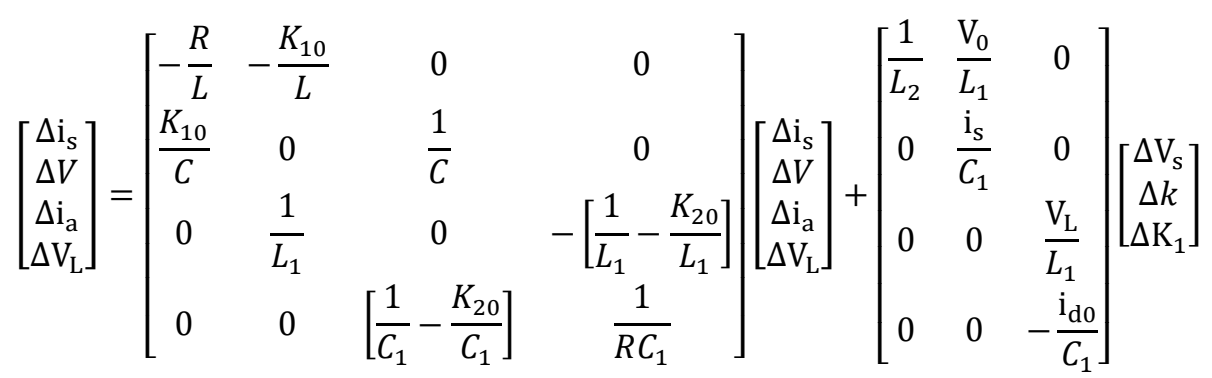

Equations (11) it is revealed that the output voltage of the AC-DC converter (connected to the DC-DC converter) can be kept constant by controlling the "K," even though the output voltage of the 
WG is " $\mathrm{V}_{\mathrm{s}}$ ". At the same time, the load voltage across the "R" can be adjusted by controlling the desired value of the duty cycle (designed), i.e., the "K1" of the DC-DC converter.

\subsection{Battery modeling}

The optimum function conditions should meet the load requirement when the battery is of sufficient size to provide the required power, then, of course, if the battery charge is large enough to be seen in the optimal setting. This is computed by the following formula:

$$
B_{a}(t)=B_{a}(t-1)+\left(\left(B_{s}(t-1)+B_{t}(t-1) C_{b a t}\right.\right.
$$

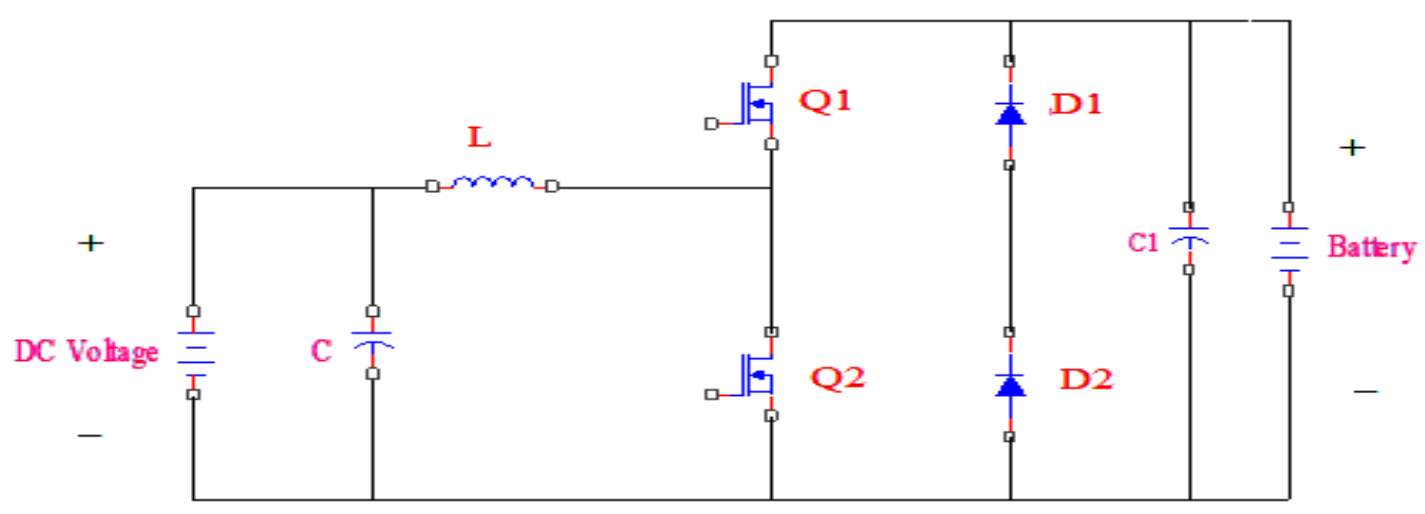

Fig. 6. Bi-directional DC-DC Converter

Where $B_{a}(t)$ is the battery charging at time $t, B_{a}(t-1)$ is the battery charge at time $t-1, B_{s}(t-$ 1 ) is the charge quantity to be stored at the time $t-1, p(t-1)$ is the total energy to provide by the battery at the time $t, C_{b a t}$ is the battery charging efficiency. The State of Charge (SOC) depends on the load requirements and the power supplied by the RES and is calculated using the following equation:

(i) For the charging mode,

$$
\operatorname{SOC}(t)=\operatorname{SOC}(t-1)+\frac{B_{\text {bat }(t)} B_{\text {char }}}{P N} .1
$$

(ii) For the discharging mode,

$$
\operatorname{SOC}(t)=\operatorname{SOC}(t-1)+\frac{B_{b a t(t)} B_{d i s}}{P_{N}} .100
$$

Among them, $\operatorname{SOC}(t)$ is the state of the battery at time $t, B_{\text {bat }(t)}$ is the power transfer during the period, $\Delta t B_{\text {char }}$ is the battery charging capacity, $B_{\text {dis }}$ is the battery discharge capacity and $P_{N}$ is the estimated battery capacity.

\subsection{Fuel Cell}

Due to fuel cell limitations, including low voltage, low current density, and transient power generation, this DC converter has become an important part of fuel cell systems for small or independent applications. With the use of DC converters, are shown in Fig. 7, these limitations can be solved with modified voltage sources from fuel cells. Various DC converters have been developed to support fuel cell systems, but DC converters are capable of conducting losses and conducting losses. Without adequate conduction and switching losses, DC converters work very efficiently. 


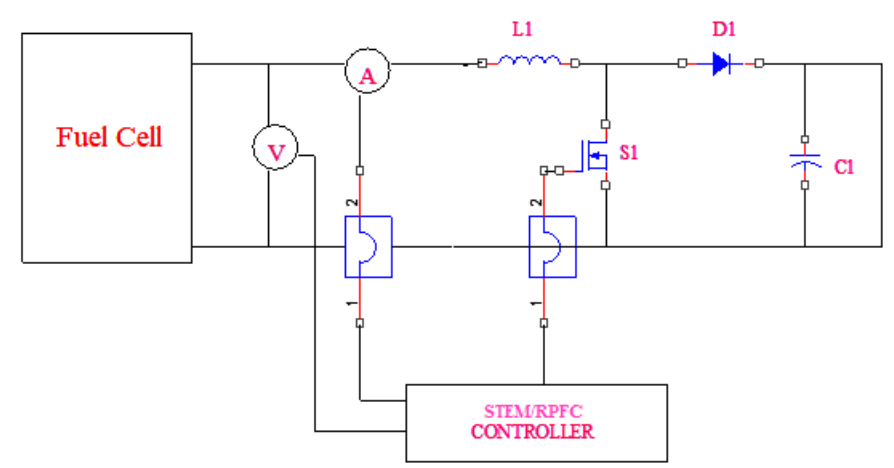

Fig. 7. Fuel Cell-Based DC-DC Converter

\subsection{Voltage Source Inverter}

A bridge-type voltage source inverter with a three-phase connection and square wave pole voltages is considered, and its circuit diagram is shown in Fig. 8. The 3-phase square wave inverter's three pole voltage usually is shifted by one-third of the output periods. Considering the way switches are counted, the number series SW1, SW2, SW3, SW4, SW5, SW6, SW1, and SW2 can be found in $\mathrm{ON}$ and OFF. At the same time, determine the switching time at 360 degrees ( $2 \pi$ radians) and see that it is 180 degrees, and the nearby switches can be turned on and off by 60 degrees. Each pole of the inverter holds power in a filler mode with the top and bottom switch. The transition sequence may be reversed by reversing the output phase sequence. Therefore, at any given time, the three switches operate as the power is noticeable. This could be the lower group switch connected to the anode DC bus.

The operations of the switches in each leg of the three-phase inverter are found to be in a complementary manner, as in the single-phase square wave inverter (Table 1). When an upper switch is on the low switch, it will cause the voltage and variation of the entire DC bus. The current distribution between the switch and diode depends on the load power factor only at that operating frequency. The control switch should vary the PWM of the inverter in general. If there is a worst-case voltage, the diodes are expected to block the peak reverse voltage equally.

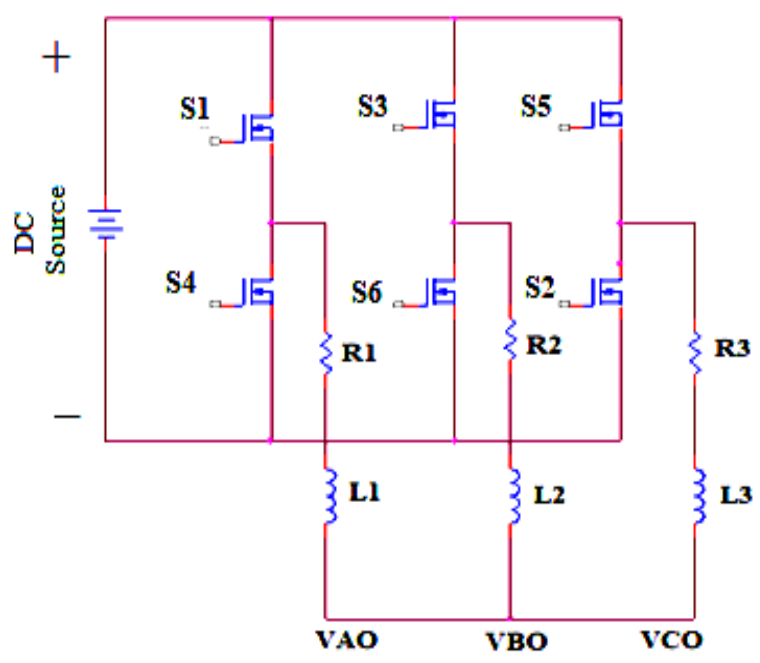

Fig. 8. Three Phase Inverter Circuit

\subsection{Energy Router Based Power Flow Analysis}

The topology of the energy router is considered to find the power flow analysis in the renewable energy system. The circuit diagram of the proposed method is shown in Fig. 9. In this work, the router will analyze the power flow in a Four-port energy converter, which includes a VSI with Grid power 
and a shared common DC power line. For the energy flow operation of the proposed system, different modes of operation are analyzed by the energy router.

Table 1. Inverter Switching Sequence

\begin{tabular}{|c|c|c|c|}
\hline Switching States & $\boldsymbol{V}_{\boldsymbol{A} \boldsymbol{O}}$ & $\boldsymbol{V}_{\boldsymbol{B} \boldsymbol{O}}$ & $\boldsymbol{V}_{\boldsymbol{C} \boldsymbol{O}}$ \\
\hline S1-S2-S6 On \& S4-S5-S3 Off & $V i$ & 0 & $V i$ \\
\hline S2-S3-S1 On \& S5-S6-S4 Off & 0 & $V i$ & $-V i$ \\
\hline S3-S4-S2 On \& S6-S1-S5 Off & $-V i$ & $V i$ & 0 \\
\hline S4-S5-S3 On \& S1-S2-S6 Off & $-V i$ & 0 & $V i$ \\
\hline S5-S6-S4 On \& S2-S3-S1 Off & 0 & $-V i$ & $V i$ \\
\hline S6-S1-S5 On \& S3-S4-S2 Off & $V i$ & $-V i$ & 0 \\
\hline S1-S3-S5 On \& S4-S6-S2 Off & $V i$ & 0 & $-V i$ \\
\hline S4-S6-S2 On \& S1-S3-S5 Off & $V i$ & $-V i$ & 0 \\
\hline
\end{tabular}

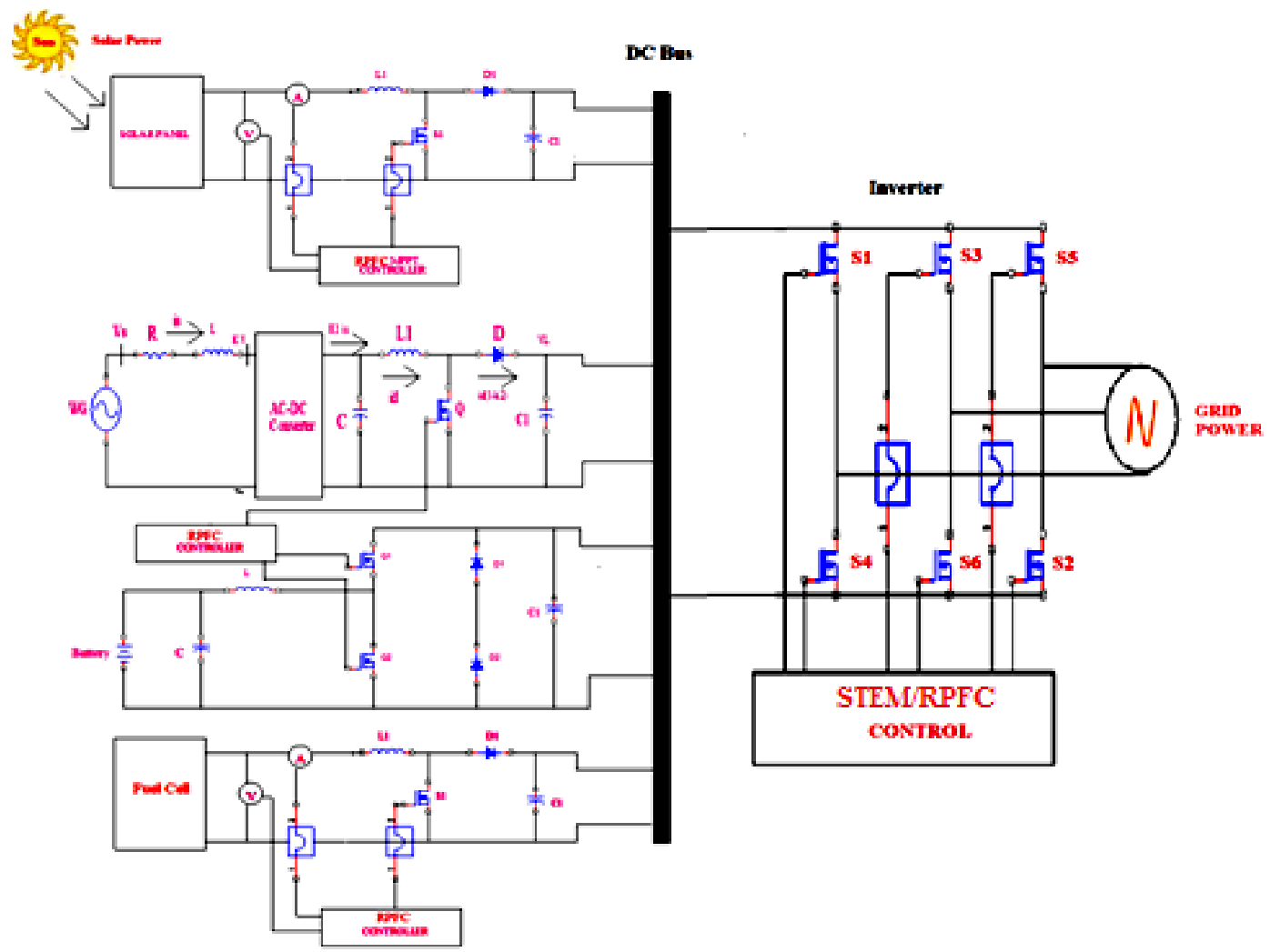

Fig. 9. Circuit diagram of the proposed system

\subsection{Substantial Transformative Energy Management (STEM) Control and Resilient Power Flow Control (RPFC) Technique}

STEM Based Flow chart is shown in Fig. 10. The proposed STEM Strategy is based on control modulation of the Hybrid Multi port converters to stabilize the grid power. A power management policy is a Multi-energy generation system designed to optimize the flow of power in a transmission system. Based on the control system, this energy router-based RPFC is generated and then predetermined compared to the value of measure power. Based on the comparative result of energy router-based power flow, RPFC has generated the pulse signal to the inverter to improve the grid power. Fig. 10 shows the implementation of an RPFC controller-based HRES system. This flowchart describes the operating procedures of a RES with a BESS system. 


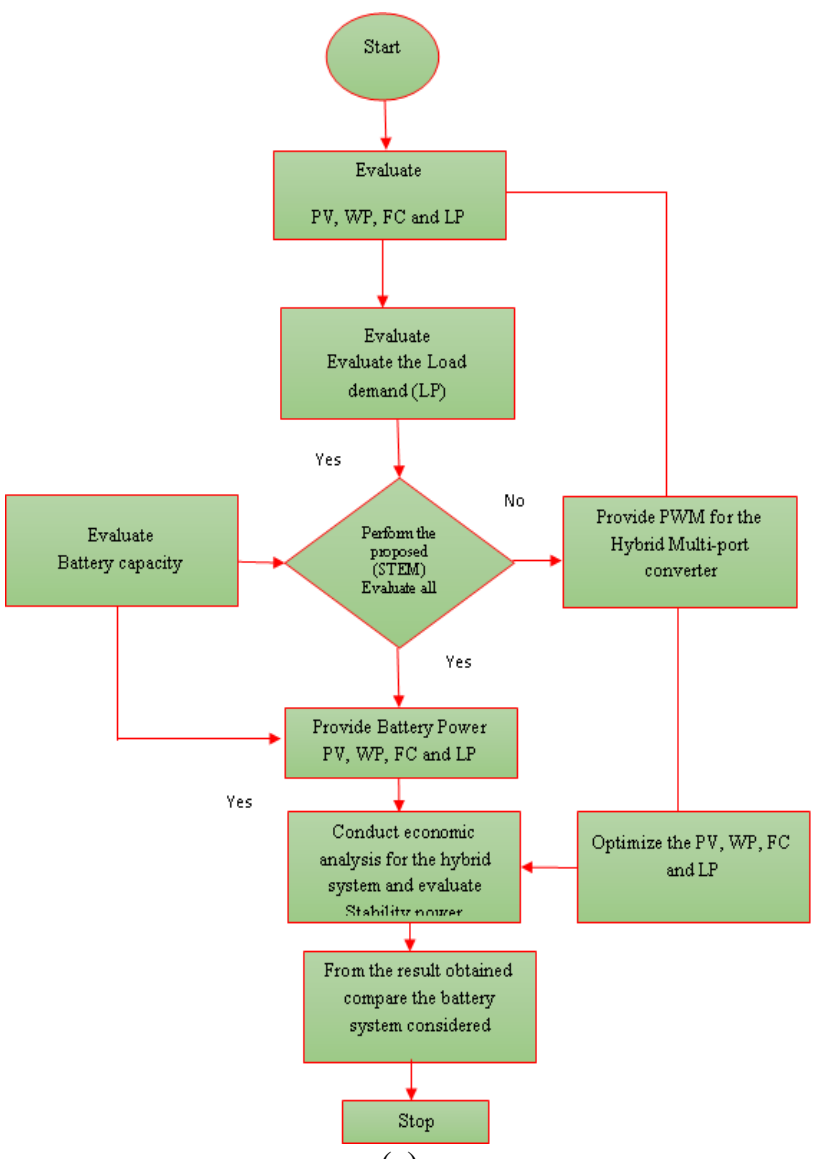

(a)

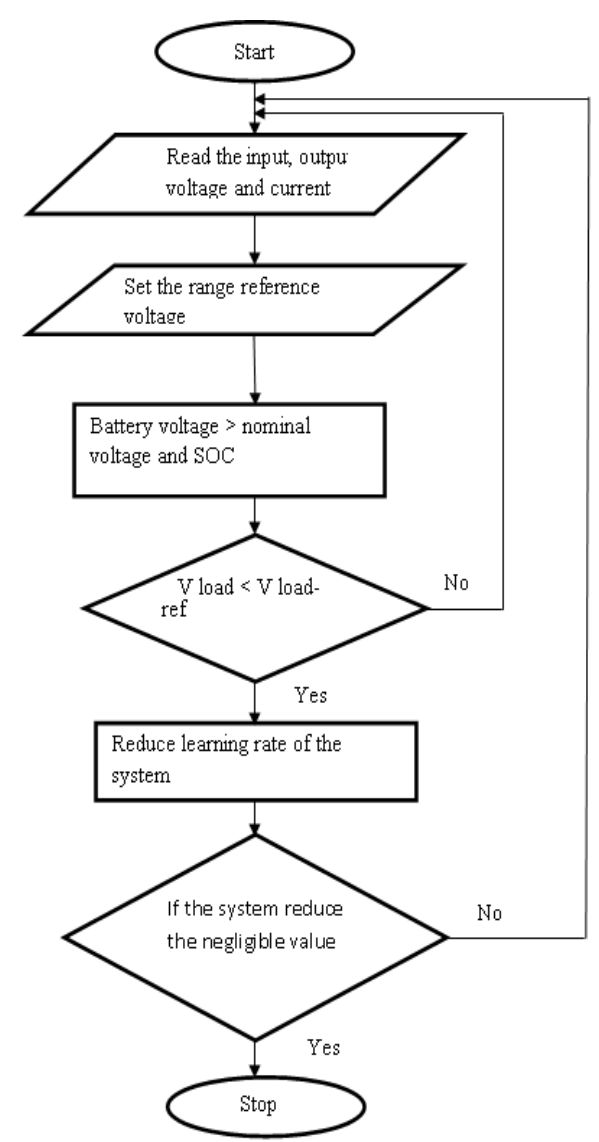

(b)

Fig. 10. Proposed (a)STEM and (b)RPFC flowchart

\section{Result and Discussion}

The present modeling approach of a MATLAB-based toolbox is presented for developing and testing the STEM and RPFC based HRES under various operational conditions. The proposed new control models are designed in a MATLAB environment. The Renewable energy management system produces an energy power source of the system, which has a different form of power generation. Insufficient sources of energy will be regulated by a converter, which improves voltage on the source site. The system power control algorithm is needed for regulating power using the proposed controller used for optimization. Fig. 11 represents the solar power generation with the Converter voltage response. The graph clearly shows the generated solar voltage is $600 \mathrm{~V}$. Also, the stability converter voltage using STEM and RPFC is represented.

Fig. 12 shows the solar output for (a) STEM (b) RPFC, and Fig. 13 demonstrates wind power generation. The above graph clearly shows the stability $\mathrm{AC}$ voltage of wind is $500 \mathrm{~V}$ with time $\mathrm{t}=1$ second. In the proposed DC-DC converter with the STEM control strategy, the generated voltage will be stabilized with fewer ripple ratios. Fig 13 shows the actual wind power generation, which has more fluctuation in the output waveform. By considering the grid and load stability operation, it could not be transferred in the grid system. 


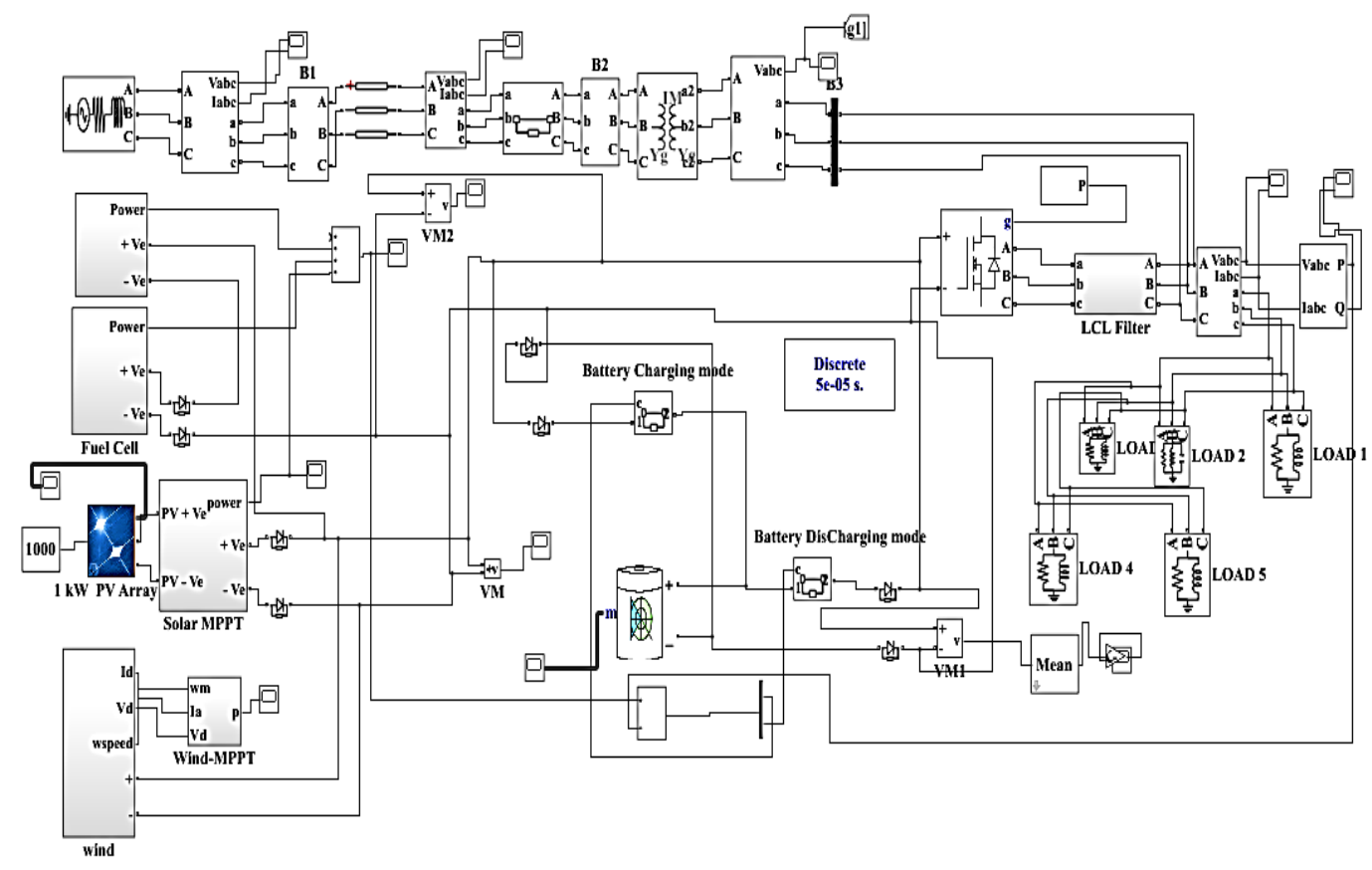

(a)

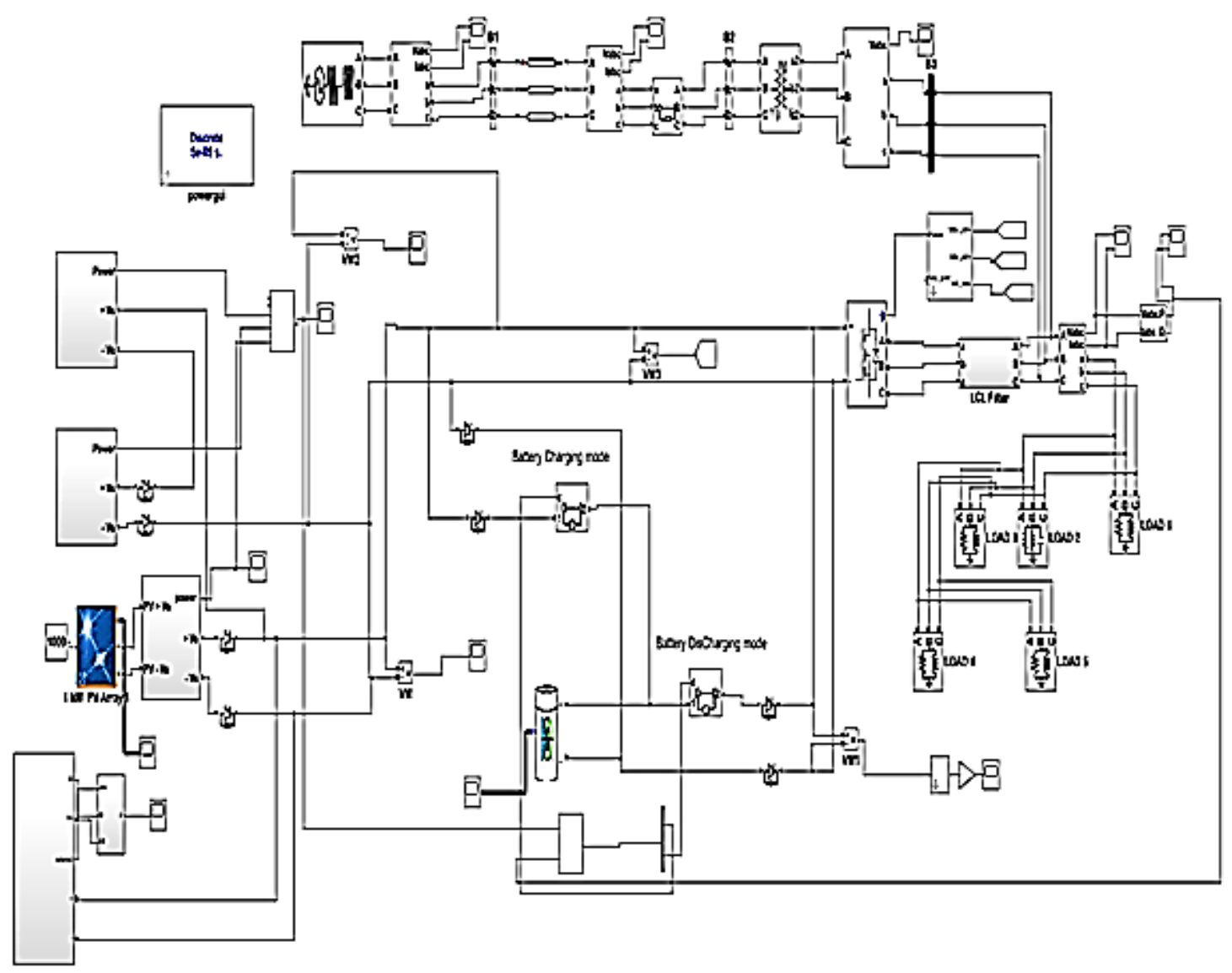

(b)

Fig. 11. Proposed Simulink Model (a) STEM (b) RPFC 


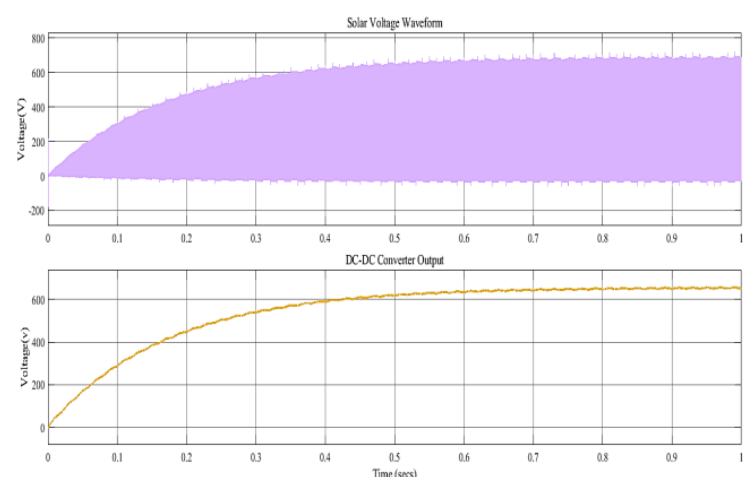

(a)

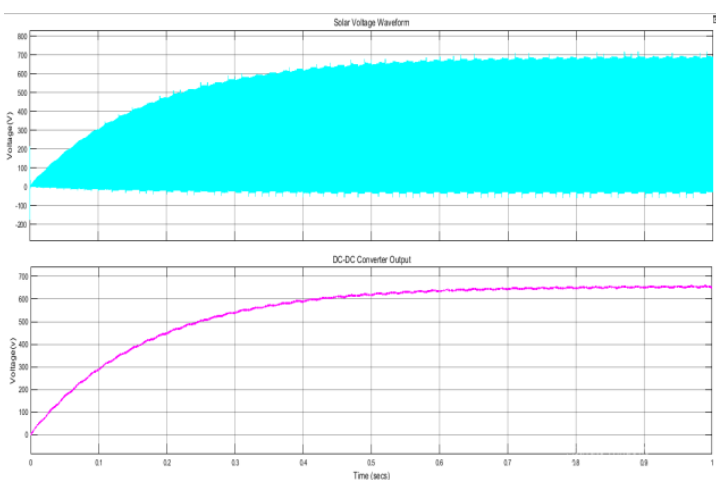

(b)

Fig. 12. Solar output power (a) STEM (b) RPFC

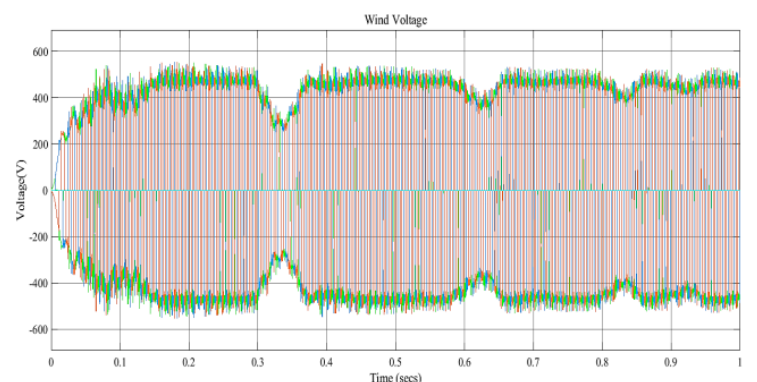

(a)

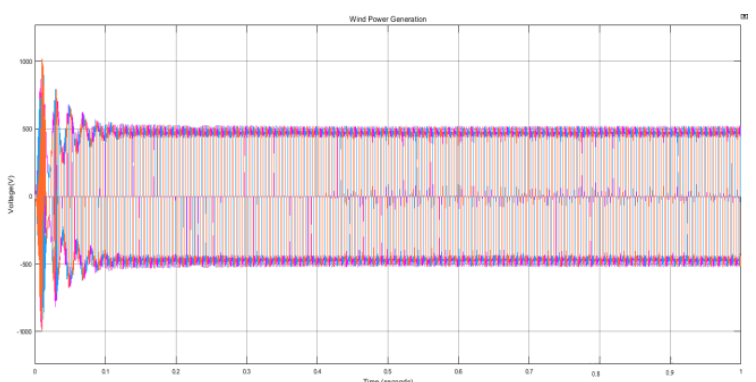

(b)

Fig. 13. Wind power (a) STEM (b) RPFC

The power variation of the wind is the initial converter to DC voltage, and then the DC-DC converter with output voltage is stabilized, which are shown in Fig. 14. The proposed controllers will stabilize the wind voltage at the time of 0.1 seconds. The two different waveforms of the wind generation system (I) Rectified output voltage of the wind generation, this process makes for stabilized the wind voltage in the DC system (II) the proposed DC-DC converter with a STEM control system will stabilize the rectified output voltage of the wind voltage. Fig. 15 Shows the Fuel Cell power generation. The above represent the three parameters of the system voltage, current, and DC-DC converter voltage.
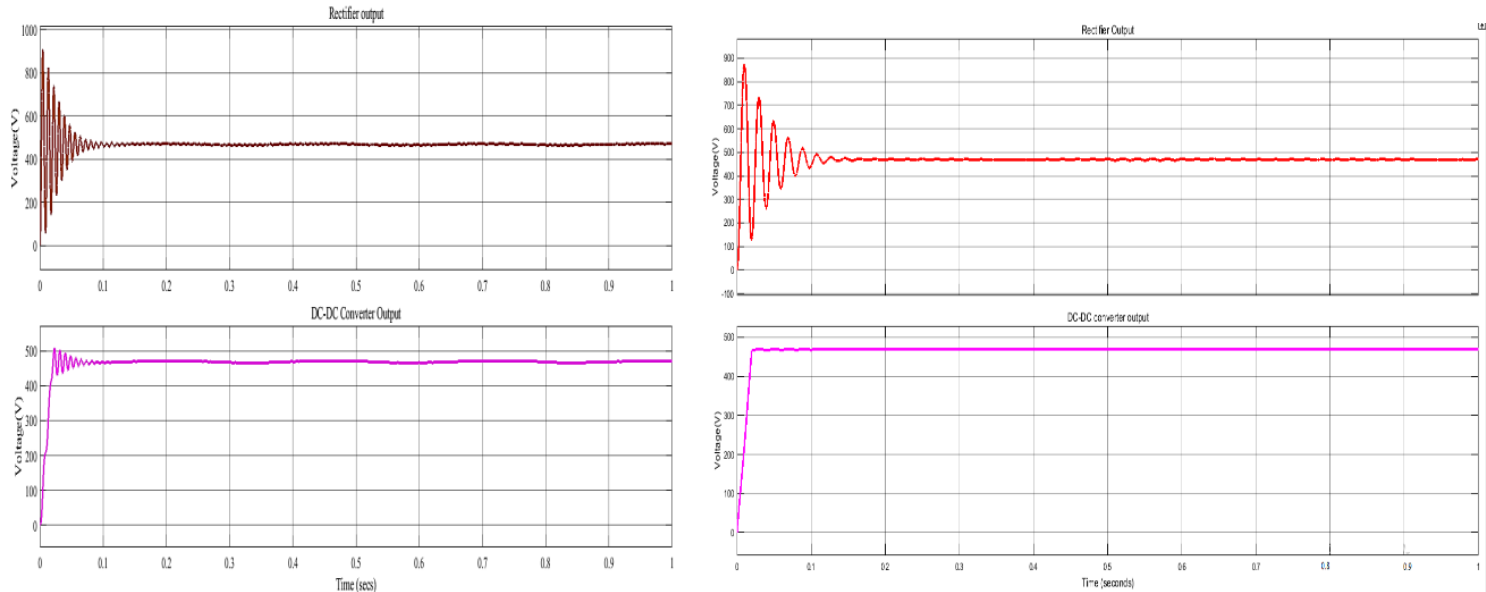

(a)

(b)

Fig. 14. Wind Energy stabilization waveform (a) STEM (b) RPFC 

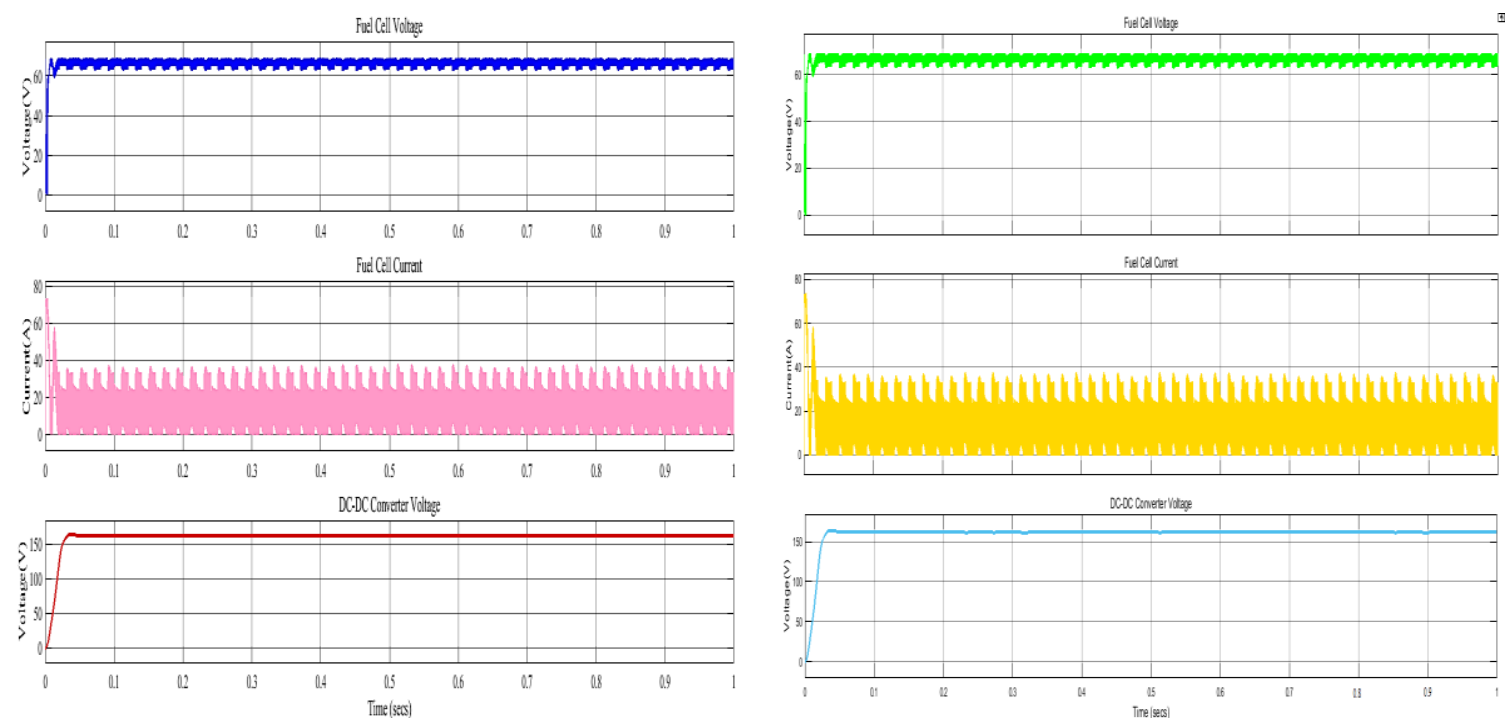

(a)

(b)

Fig. 15. Fuel Cell Generation with Boost Converter Waveform (a) STEM (b) RPFC

The energy management is proceeding with the battery system, and during the power generation of the renewable energy resources, the battery is in a charging state. If there is energy uncertainty, the battery power is delivered to stabilize the power by using a bi-direction DC-DC converter. This process is applicable to the charging state of the battery shown in Fig. 16.

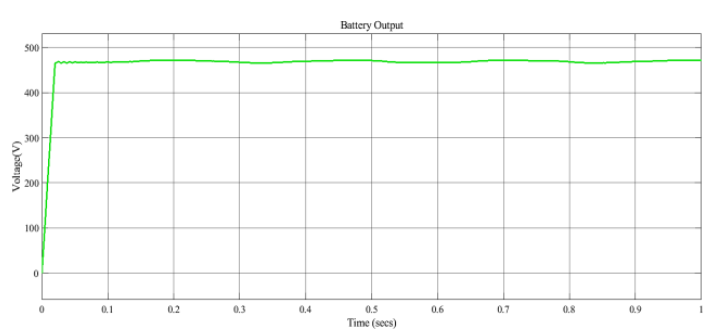

(a)

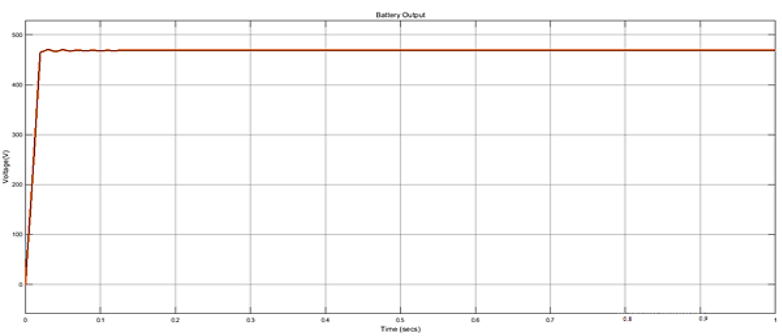

(b)

Fig. 16. Battery Output (a) STEM (b) RPFC

Fig. 17 shows the grid power waveform of the HRES system. The proposed controller RPFC will stabilize the renewable energy generation sources. The stabilized HRES power will be fed to the load system for the performance analysis. Fig. 18 Representing the load voltage and current waveforms in a different time period relative to each other. The waveform confirms that the Power Factor is almost unity for any load on the RPFC controller.

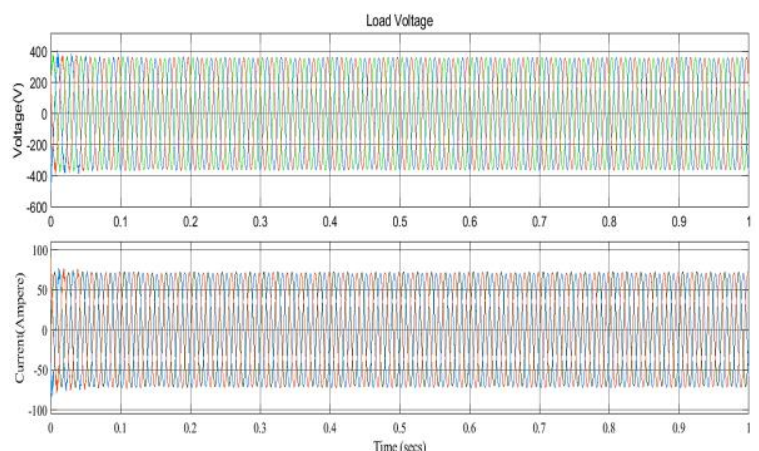

(a)
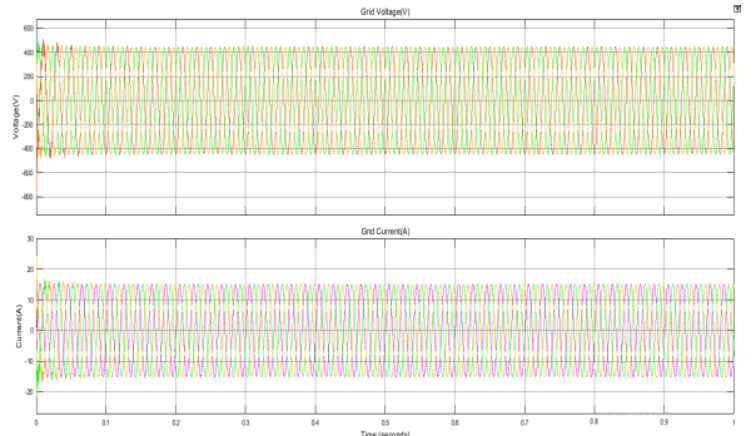

(b)

Fig. 17. Grid Power Waveform (a) STEM (b) RPFC 
Fig. 19 shows the Total Harmonics Distortions (THD) analysis of the proposed Hybrid Multi port converter model by using the Resilient Power Flow Control. The STEM controller control strategy will produce $2.52 \%$ of the THD Ratio, and the RPFC control strategy will produce $1.68 \%$ of the THD Ratio. It is clearly shown that the proposed RPFC controller gives better performance compared to the other controllers.

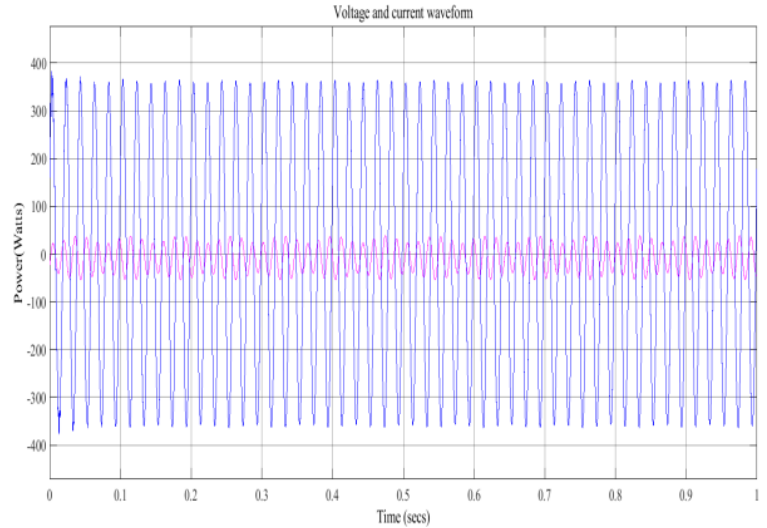

(a)

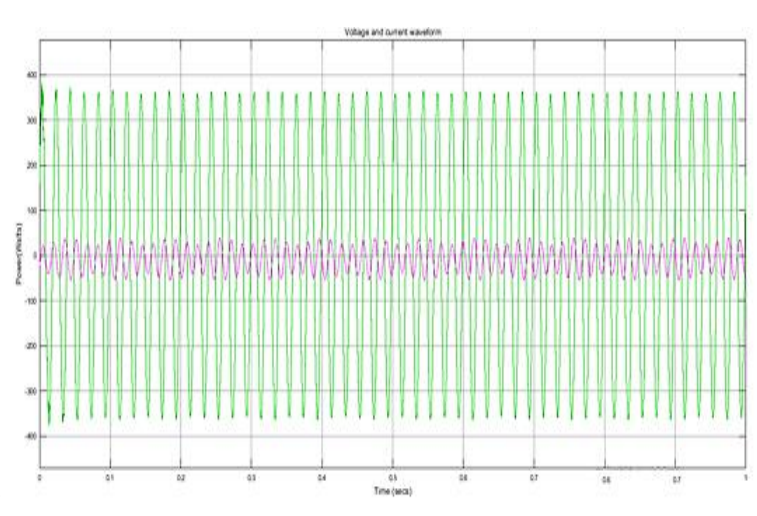

(b)

Fig. 18. Load current and Voltage waveform (a) STEM (b) RPFC

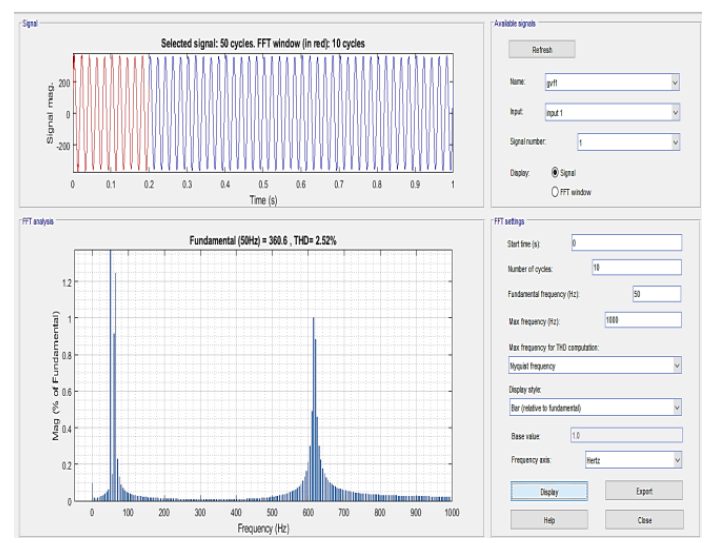

(a)

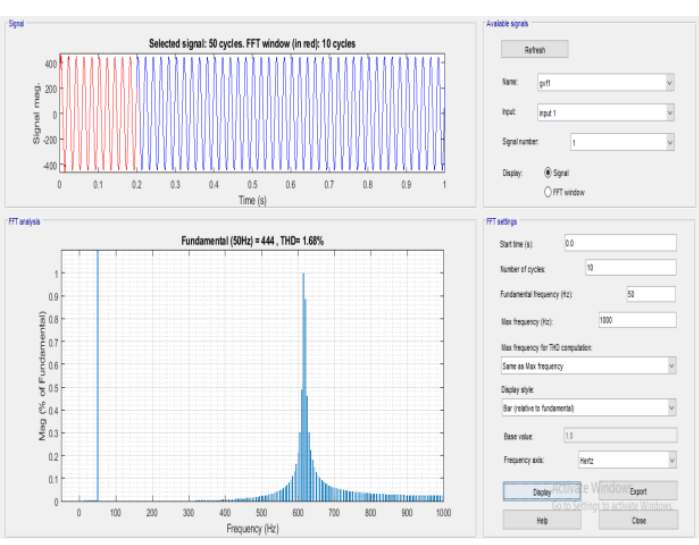

(b)

Fig. 19. THD analysis (a) STEM (b)RPFC

Table 2 represents the performance analysis of the hybrid multi-port converter system based on the parameters. It is clearly shown that the proposed control RPFC strategy produces an efficient result compared with the STEM, fuzzy and conventional controllers.

Table 2. Performance analysis of the Hybrid power generation system

\begin{tabular}{|l|c|c|c|c|}
\hline Controller & $\begin{array}{c}\text { Steady state error } \\
(\boldsymbol{\%})\end{array}$ & $\begin{array}{c}\text { Execution } \\
\text { Time (Sec) }\end{array}$ & THD (\%) & $\begin{array}{c}\text { Efficiency } \\
(\boldsymbol{\%})\end{array}$ \\
\hline PI & 1.536 & 0.889 & 8.9 & 86.5 \\
\hline PID & 1.2365 & 0.8715 & 7.23 & 88.4 \\
\hline Fuzzy & 0.821 & 0.7216 & 5.06 & 90.1 \\
\hline STEM & 0.513 & 0.6319 & 2.52 & 97.2 \\
\hline RPFC & 0.326 & 0.536 & 1.68 & 98.25 \\
\hline
\end{tabular}

Table 3 describes the performance analysis of the Power Factor (PF) variation for the HRES system under load varying conditions. In the comparison between Table 2 and Table 3, it is clearly shown that the proposed RPFC controller gives better performance compared to the conventional controllers and STEM techniques. 
Table 3. Performance analysis of the power factor for various Load

\begin{tabular}{|c|c|c|c|c|c|}
\hline $\begin{array}{c}\text { Load } \\
(\mathbf{W})\end{array}$ & PI & PID & Fuzzy & STEM & RPFC \\
\hline 0 & 0.9949 & 0.9954 & 0.9958 & 0.9971 & 0.9989 \\
\hline 200 & 0.9945 & 0.9951 & 0.9955 & 0.9965 & 0.9972 \\
\hline 400 & 0.9941 & 0.9948 & 0.9949 & 0.9961 & 0.9970 \\
\hline 600 & 0.9938 & 0.9945 & 0.9947 & 0.9958 & 0.9968 \\
\hline 800 & 0.9934 & 0.9941 & 0.9945 & 0.9955 & 0.9962 \\
\hline 1000 & 0.9932 & 0.9940 & 0.9941 & 0.9952 & 0.9958 \\
\hline
\end{tabular}

Fig. 20 shows the comparative analysis of the HRES system for the power factor under load varying conditions. When compared with other conventional controllers, the proposed RPFC Controller will produce efficient results under (0-1000) load varying conditions compared to the controllers.

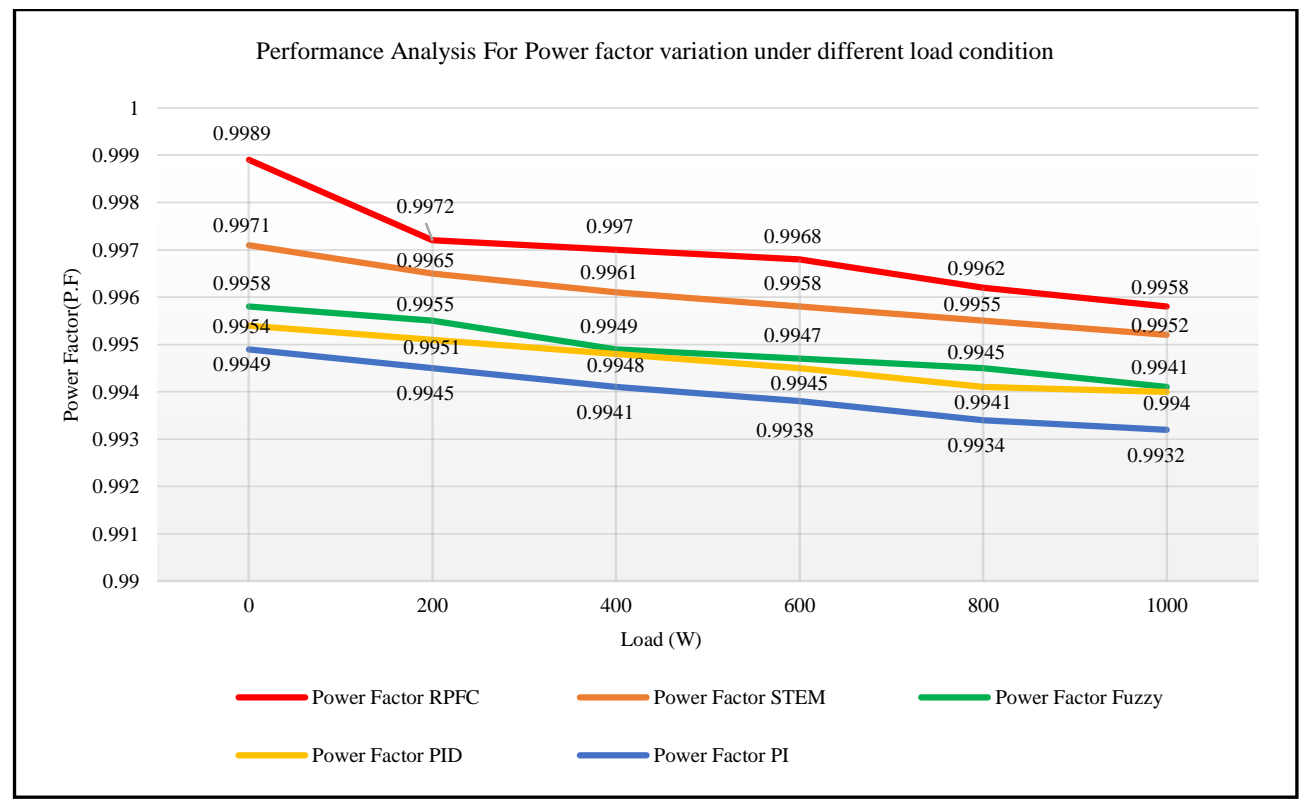

Fig. 20. Comparative analysis of Power Factor under load varying condition

\section{Conclusion}

The proposed RPFC technique in the hybrid multiport converter system shows the betteroptimized energy management system in the smart grid application. The simulation is done from the dynamic model of the simulated Hybrid multiport grid system, and from this simulation, it is possible to understand how to maintain the parameters of the multi-power generation with battery-based energy management. The purpose of the proposed smart energy management is to reduce operating costs and reduce the impact of microgrids on the environment while significantly improving the economic and technical efficiency of the power generation system. The proposed RPFC control ensures power management between renewable energy generation, energy storage, and load during the Hybrid multiport converter to perform its functions. The simulation results clearly show that the proposed RPFC controller shows high performance under the steady-state condition and efficiency analysis. It produces the least THD of $1.68(\%)$ compared with the conventional methods. In the future, the proposed controller can be focused on developing a soft-switching of inverter for grid-connected systems for different application purposes.

Author Contribution: All authors contributed equally to the main contributor to this paper. All authors read and approved the final paper. 
Funding: This research received no external funding.

Conflicts of Interest: The authors declare no conflict of interest.

\section{Reference}

[1] Y. Yang, W. Pei, W. Deng, and S. Zhang, "Benefit Analysis of Using Multi-port and Multi-function Power Electronic Transformer Connecting Hybrid AC/DC Power Grids," The Journal of Engineering, vol. 2019, no. 16, pp. 1076 - 1080, 2019, https://doi.org/10.1049/joe.2018.8446.

[2] Q. Xiao, H. Jia, B. Liang, and J. He, "Current balancing control for multi-port hybrid AC/DC micro grid," 2017 IEEE Power \& Energy Society General Meeting, 2017, pp. 1-5, https://doi.org/10.1109/PESGM.2017.8273788.

[3] R. Xu, X. Wu, H. Liu, Z. Zhou, H. Yin, T. Lan, Y. Lan, "Research on Control Strategy for Multi-port Power Electronics Transformer Based on Interphase Coupling MMC Topology," 2019 22nd International Conference on Electrical Machines and Systems (ICEMS), 2019, pp. 1-5, https://doi.org/10.1109/ICEMS.2019.8922102.

[4] C. Tu, L. Guan, F. Xiao, and Z. Lan, "Study on a novel multi-port energy router for AC-DC hybrid microgrid," 2018 13th IEEE Conference on Industrial Electronics and Applications (ICIEA), 2018, pp. 2654-2659, https://doi.org/10.1109/ICIEA.2018.8398159.

[5] Y. Shao, X. Deng, S. Lu, and S. Li, "A New Multi-Port Power Electronic Transformer for Distribution Grid," 2019 22nd International Conference on Electrical Machines and Systems (ICEMS), 2019, https://doi.org/10.1109/ICEMS.2019.8921513.

[6] M. Rouhani, and G. J. Kish, "Multiport DC-DC-AC Modular Multilevel Converters for Hybrid AC/DC Power Systems," IEEE Transactions on Power Delivery, vol. 35, no. 1, pp. 408-419, 2019, https://doi.org/10.1109/TPWRD.2019.2927324.

[7] C. Ren, L. Liu, X. Han, B. Zhang, L. Wang, and P. Wang, "Multi-mode Control for Three-phase Bidirectional AC/DC Converter in Hybrid Micro grid under Unbalanced AC voltage Conditions," 2019 IEEE Energy Conversion Congress and Exposition (ECCE), 2019, https://doi.org/10.1109/ECCE.2019.8912259.

[8] A. Elrayyah, "Control Algorithms to Establish Hybrid AC/DC Distribution Systems Using Conventional Three Phase Inverters," 2019 IEEE Energy Conversion Congress and Exposition (ECCE), 2019, https://doi.org/10.1109/ECCE.2019.8912509.

[9] M. V. Samith and M. R. Rashmi, "Controller for integrating small scale power generation to hybrid AC/DC grid," 2016 International Conference on Inventive Computation Technologies (ICICT), 2016, https://doi.org/10.1109/INVENTIVE.2016.7830098.

[10] W. Guo, X. Han, C. Ren, and P. Wang, "The control method of bidirectional AC/DC converter with unbalanced voltage in hybrid micro-grid," 2015 IEEE 10th Conference on Industrial Electronics and Applications (ICIEA), 2015, https://doi.org/10.1109/ICIEA.2015.7334143.

[11] W. Xu, A. Li, Y. Su, M. Zhu, X. Ouyang, and X. Yang, "Optimal Expansion Planning of AC/DC Hybrid System Integrated with VSC Control Strategy,” 2019 IEEE Innovative Smart Grid Technologies - Asia (ISGT Asia), 2019, https://doi.org/10.1109/ISGT-Asia.2019.8881734.

[12] X. Liu, and Y. Liu, "Optimal planning of AC-DC hybrid transmission and distributed energy resource system: Review and prospects," CSEE Journal of Power and Energy Systems, vol. 5, no. 3, pp. 409-422, 2019, https://doi.org/10.17775/CSEEJPES.2019.00540.

[13] M. Shojaie and O. A. Mohammed, "A Multi-input DC-DC Converter with AC-DC PFC Buck-boost Stage for Hybrid Energy storage Systems,” SoutheastCon 2018, 2018, pp. 1-5, https://doi.org/10.1109/SECON.2018.8478879

[14] R. Barrera-Cardenas, O. Mo, and G. Guidi, “Optimal Sizing of Battery Energy Storage Systems for Hybrid Marine Power Systems,” 2019 IEEE Electric Ship Technologies Symposium (ESTS), 2019, https://doi.org/10.1109/ESTS.2019.8847932.

[15] Z. Zheng, J. Zheng, W. Zhao, and Z. Han, "Research on Dynamic Voltage Characteristics of AC/DC Hybrid System Based on PET," 2019 IEEE Innovative Smart Grid Technologies - Asia (ISGT Asia), 2019, https://doi.org/10.1109/ISGT-Asia.2019.8881201.

[16] C. Petino, P. Ruffing, and A. Schnettler, "Intersystem fault clearing in hybrid AC/DC power systems with full bridge modular multilevel converters," 13th IET International Conference on AC and DC Power Transmission (AC-DC 2017), 2017, https://doi.org/10.1049/cp.2017.0020. 
[17] H. M. A. Ahmed, A. B. Eltantawy, and M. M. A. Salama, "A Generalized Approach to the Load Flow Analysis of AC-DC Hybrid Distribution Systems," IEEE Transactions on Power Systems, vol. 33, no. 2, pp. 2117 - 2127, 2018, https://doi.org/10.1109/TPWRS.2017.2720666.

[18] Y. Zhu, S. Shi, S. Cheng, R. Ding, X. Du, and F. Zhuo, "Topology, Modulation and Control Strategy of a Multi-port DC/DC Converter based on Modular Multilevel Converter," 2019 IEEE 10th International Symposium on Power Electronics for Distributed Generation Systems (PEDG), 2019, https://doi.org/10.1109/PEDG.2019.8807722.

[19] C. Nagarajan and M. Madheswaran, "Experimental Study and steady state stability analysis of CLL-T Series Parallel Resonant Converter with Fuzzy controller using State Space Analysis," Iranian Journal of Electrical and Electronic Engineering, vol. 8, no. 3, pp. 259-267, 2012, http://ijeee.iust.ac.ir/browse.php?a_id=376\&sid=1\&slc_lang=en.

[20] E. Geetha and C. Nagarajan, "Induction Motor Fault Detection and Classification Using Current Signature Analysis Technique," 2018 Conference on Emerging Devices and Smart Systems (ICEDSS), 2018, pp. 48-52, https://doi.org/10.1109/ICEDSS.2018.8544272.

[21] C. Nagarajan, M. Muruganandam and D. Ramasubramanian, "Analysis and Design of CLL Resonant Converter for Solar Panel-Battery systems," International Journal of Intelligent systems and Applications (IJISA), vol. 5, no. 1, pp. 52-58, 2012, https://doi.org/10.5815/ijisa.2013.01.05.

[22] C. Nagarajan and M. Madheswaran, "Stability Analysis of Series Parallel Resonant Converter with Fuzzy Logic Controller Using State Space Techniques," Electric Power Components and Systems, vol. 39, no. 8, pp.780-793, 2011, https://doi.org/10.1080/15325008.2010.541746.

[23] K. Umadevi and C. Nagarajan, "High Gain Ratio Boost-Fly Back DC-DC Converter using Capacitor Coupling," 2018 Conference on Emerging Devices and Smart Systems (ICEDSS), 2018, pp. 64-66, https://doi.org/10.1109/ICEDSS.2018.8544321.

[24] S. S. Kumar, B. Swapna, Dr. C. Nagarajan, "Modeling and Control for Smart Grid Integration with MPPT of Solar/Wind Energy Conversion System," International Journal of Innovative Research in Science, Engineering and Technology, vol. 3, pp. 920-929, 2014, https://www.rroij.com/open-access/modelingand-control-for-smart-grid-integrationwith-mppt-of-solarwind-energyconversion-system.pdf.

[25] Tharani, B Nagarajan, C, “An AC-DC/DC-DC hybrid multi-port embedded energy router based Steadystate power flow optimizing in power system using substantial transformative energy management strategy," Journal of Ambient Intelligence and Humanized Computing, vol. 12, no. 5, pp. 5687-5707, 2020, https://doi.org/10.1007/s12652-020-02362-8. 